\title{
La historia del cooperativismo en Colombia: hitos y periodos
}

\author{
Luz Patricia Pardo-Martínez ${ }^{\star}$, María Victoria Huertas de Mora ${ }^{\star *}$
}

* Doctora en Investigación Histórica. Directora del grupo de investigación Arte solidario. Profesora titular de la Maestría en Gestión de las Organizaciones, Universidad Cooperativa de Colombia, Bogotá, Colombia.

Correo electrónico: luz.pardo@campusucc.edu.co

** Magíster en Contabilidad y Auditoría de Gestión. Miembro del grupo de investigación Arte solidario. Profesora titular de la Maestría en Gestión de las Organizaciones, Universidad Cooperativa de Colombia, Bogotá, Colombia.

Correo electrónico:

marivihuertas@yahoo.com

Recibido: 18 de enero del 2014 Aprobado: 8 de mayo del 2014

Cómo citar este artículo: Pardo-Martínez, L. P. y Huertas de Mora, M. V. (2014). La historia del cooperativismo en Colombia: hitos y periodos. Cooperativismo \& Desarrollo, 104(22), 49-61. doi: http://dx.doi. org/10.16925/co.v22i104.970

\section{Resumen}

La línea de investigación que soporta el presente artículo se orientó a precisar los siguientes ejes fundamentales: el primero, identificar cuáles tipos de cooperativas - y su caracterización - se han dado en Colombia, y el segundo, establecer cuáles hitos han marcado y definido momentos históricos. El énfasis centra la mirada investigativa en indagar la viabilidad, utilidad y correspondencia de las organizaciones cooperativas con la doctrina filosófica del sector; analizar el aporte de las cooperativas según sus prácticas al desarrollo y potenciación de su dimensión social, a la vez que la incidencia de sus comportamientos en la consolidación de la organización con respecto a la comunidad local y nacional; por último, establecer periodos históricos de desarrollo de las organizaciones cooperativas en Colombia.

Palabras clave: caracterización, cooperativas, historia, hitos.

\section{The History of Cooperativism in Colombia: Milestones and Periods}

\begin{abstract}
The line of research that supports this article aims to clarify the following fundamental axes: first of all, to identify which types of cooperatives have arisen in Colombia, along with their characterization, and secondly to establish the milestones that have marked and defined historic periods. The research focuses on addressing the feasibility, usefulness and correspondence of cooperative organizations with the philosophical doctrine of the sector; analyzing the contribution of cooperatives, according to their practices, to development and to boosting their social dimension, along with the influence of their behaviors on consolidation of such organizations with respect to local and national communities; and finally, to establish historical periods of development of cooperative organizations in Colombia.
\end{abstract}

Keywords: characterization, cooperatives, history, milestones

\section{A história do cooperativismo na Colômbia: marcos e períodos}

\section{Resumo}

A linha de pesquisa que apoia este artigo teve como objetivo precisar os seguintes eixos fundamentais: o primeiro, identificar quais tipos de cooperativas - e sua caracterização- deram-se na Colômbia, e o segundo, estabelecer quais marcos caracterizaram e definiram momentos históricos. A ênfase concentra o olhar investigativo em indagar a viabilidade, a utilidade e a correspondência das organizações cooperativas com a doutrina filosófica do setor; analisar a contribuição das cooperativas segundo suas práticas ao desenvolvimento e reforço de sua dimensão social, bem como o impacto de seus comportamentos na consolidação da organização na comunidade local e nacional; por último, estabelecer períodos históricos de desenvolvimento das organizações cooperativas na Colômbia.

Palavras-chave: caracterização, cooperativas, história, marcos. 


\section{Introducción}

El presente estudio - "La historia del cooperativismo en Colombia: hitos y periodos" - se propone determinar y analizar las prácticas que han asegurado la viabilidad y permanencia de las organizaciones cooperativas y han facilitado el desarrollo social y económico de sus miembros, así como el de las comunidades donde actúan. Constituye un elemento adicional en el estudio identificar los modelos internacionales que han sido referentes para estas organizaciones y su grado de influencia.

Con respecto al desarrollo del documento, es posible evidenciar que:

En primer lugar, se muestra el interés por rescatar el fundamento central de la organización cooperativa en sus conceptos básicos de asociado, dueño, usuario y autogestor empresarial, que son pertinentes a todos aquellos que participan en estas organizaciones, $y$ entender esas relaciones - a veces polémicas y antagónicas en la organización cooperativa - tomando la experiencia de ahorro y crédito.

En segundo lugar, y como un aporte al análisis y reflexión del mismo, a partir de los hallazgos encontrados en el grupo estudiado, se aborda la pregunta: ¿cuál ha sido la incidencia de las diversas prácticas de ahorro y crédito en las cooperativas de Colombia, y en el desarrollo social y doctrinal del sector?

El movimiento cooperativo, desde su fundamento doctrinal, se orienta en un marco de justicia y solidaridad al buscar beneficios económicos y sociales, según el concepto de distribución de los resultados. Tiende a hacer práctica la igualdad y la equidad; ello enmarcado en un criterio de responsabilidad social como principio que obliga a las cooperativas para con sus dueños (asociados), familias, empleados y comunidad, en el cual se entrelazan el aspecto económico como base y el aspecto social como finalidad.

Esta diversidad expresa una gran riqueza organizativa y promueve gran actividad (proactividad), a la hora de atender las particularidades de las regiones y sectores sociales en los que actúa, como movimiento social y como organización empresarial, teniendo en cuenta una perspectiva histórica.

\section{Periodos históricos e hitos de desarrollo del cooperativismo en Colombia}

Tomando en cuenta la construcción ilustrativa que nos hacen los autores del libro Estado del arte del sector solidario en Colombia (Pardo, Serrano y Jaramillo,
2006), se apropian como referentes para este trabajo cinco periodos históricos en el desarrollo del sector cooperativo en Colombia, a saber:

- Primer periodo (1930-1945): surgimiento del mutualismo y el cooperativismo;

- Segundo periodo (1946-1964): promoción y expansión del cooperativismo;

- Tercer periodo (1965-1976): consolidación del cooperativismo;

- Cuarto periodo (1977-1990): crecimiento como sector y movimiento social; y

- Quinto periodo (1991-2010): crisis y economía solidaria o de la solidaridad.

Con este punto de partida, se aborda el presente trabajo, para establecer, en esta perspectiva histórica de periodicidad, los diferentes hitos que marcan la vida de estas organizaciones para el caso colombiano, $\mathrm{e}$ identificar los diferentes tipos de cooperativas y su caracterización.

\section{Primer periodo (1930-1945): surgimiento del mutualismo y el cooperativismo}

En este periodo, se destacan los aportes al conocimiento y la praxis cooperativa a los cuales contribuye la producción de los autores y promotores extranjeros Antonio Fabra (1944, 1945), George Fouquet (1944), Luis Nazario y Margaret Digby, entre varios también mencionados, según lo registra la obra de Pardo, Serrano y Jaramillo (2006):

Así mismo se destaca el trabajo de difusión filosóficodoctrinario y de orientación educativa y técnica de un selecto grupo de escritores nacionales, entre los cuales se destacan: Francisco Luis Jiménez, Antonio García Nossa, el sacerdote Jesuita Francisco Javier Mejia, Marco Naranjo López, Samuel Ruiz Lujan, José Vásquez, Estanislao Rojas,Jorge Manostoque Valero, Narses Salazar Cuartas y Carlos Uribe Garzón (p. 67).

Los autores relacionados desarrollan durante este periodo un intenso trabajo intelectual de producción literaria y técnica, especialmente en temas de interés para el momento histórico que caracteriza al cooperativismo en Colombia. Los temas doctrinales y legales son los que priman. Otros más específicos, tales como: cooperativas de consumo, el porvenir de las cooperativas en América, la educación cooperativa, las normas 
legales sobre cooperativas, la cooperación como nuevo orden económico, las cajas populares de crédito, sindicalismo y cooperativismo, cooperativas agropecuarias y de comercialización, etc., muestran la preocupación por incidir con difusión axiológica y doctrinal de conjunto y construir movimiento, pero también por brindar orientación en institucionalidad, herramientas normativas y de buenas prácticas, importantes para la constitución y en la vida inicial de las organizaciones.

La mayoría de los autores de la época se destaca por sus nexos con la academia. Las universidades Libre, de Antioquia, Comercial (del Gimnasio Moderno, hoy no vigente), Católica Bolivariana, Javeriana, del Cauca, Colegio Mayor de Nuestra Señora del Rosario, Nacional de Colombia y Santo Tomás de Aquino vinculan a estas personas - algunos no profesionales disciplinares, pero sí conocedores del quehacer de la organización social - como sus docentes de cátedra, y les permiten publicar sus escritos.

Es por lo anterior que en este periodo se observa una tendencia marcada por brindar soporte y justificación desde lo doctrinal a las aspiraciones de lo normativo. Según lo registra Uribe (2004), en Colombia, la Iglesia católica tiene una marcada influencia a través de sus sociedades católicas de fieles laicos, quienes promueven el mutualismo y el cooperativismo con mutualidad, aunque por lo mencionado, muy inhibido en su dependencia de los gobiernos y por la normatividad promotora, con la que se distingue este inicial periodo de promoción a organizaciones populares y laborales, en un momento de desarrollo del país en el cual las obras públicas y la industrialización impulsan las concentraciones y migración de jóvenes a los centros urbanos, además de una actividad política de pre y posguerra mundial que replican debates de los partidos socialistas y comunistas en el mundo.

Las cooperativas eran las organizaciones preferidas por los gobiernos de turno, que aceptan y construyen una política de promoción a partir de leyes, subsidios y preferencias. Son estas organizaciones sociales las que reciben un primer "reconocimiento como operadores privilegiados del ahorro" (Congreso de la República de Colombia, 1932) en Colombia, junto con las cajas laborales (sindicales), las cajas de ahorro de las asociaciones sociales (Caja Social de Ahorros), desde la naciente pero importante política de ahorros del momento y su operador estatal, la Caja de Crédito Agrario, Industrial y Minero, transformada hoy en banco comercial luego de sus varias reestructuraciones. La ley dota a este grupo de actores sociales y económicos de un organismo de vigilancia y control: la Superintendencia Nacional de Cooperativas, creada en el año de 1933.

Es así que las cooperativas, como una alternativa económica de organización, eran consideradas como actores clave en el desarrollo de una política pública para el consumo y la producción, desde una mirada a su auge en Europa y Norteamérica, con exitosos programas de solución a los estragos de la posguerra, ponderadas en las nuevas tendencias de organización mundial y modelación económico-social que se gestionan para la época.

Por su parte, otras formas solidarias e históricas existentes - ya sean originarias de las comunidades indígenas en los diversos territorios o, incluso, aquellas otras nuevas formas mutuales y de asociación-, por razón de los privilegios dados a las cooperativas, se convierten en dependientes, se vuelven invisibles o siguen operando por supervivencia, pero lo hacen al ritmo de la autonomía o de las urgencias de las comunidades que atienden.

\section{Segundo periodo (1946-1964): promoción y expansión del cooperativismo}

Entre el año 1953 y hasta el año de 1962, las cooperativas disfrutan de una especial atención del Estado, de privilegios y de innumerables ventajas, incluidas aquellas de tipo fiscal. Su promoción y crecimiento en número y cobertura de comunidades son significativos. Las estadísticas reportadas por sus organismos de representación registran, para 1960, 425 cooperativas con 234392 asociados, siendo las más numerosas las de consumo, vivienda, comercialización agrícola, transporte y servicios especiales. Coincide ello con la época de la segunda posguerra, con una masiva acogida de grupos inmigrantes y la organización de un frente nacional político en Colombia.

Asimismo, en este periodo se crean organismos de grado superior como Uconal, Ascoop, Cecora, Ucopan y Cencoa, que integran, respectivamente, a las cooperativas de crédito y ahorro; multiactivas y de consumo; agropecuarias de la reforma agraria; agrícolas de producción y mercadeo y las de caficultores. Las organizaciones potencian las actividades de la Superintendencia Nacional de Cooperativas y logran la reforma y modernización de la legislación cooperativa vigente desde los años 1930 con la expedición del Decreto ley 1598 de 1963, que orienta el control estatal del sector por 25 años. 
Entre 1960 y 1965, se presenta un periodo de expansión debido a la labor promocional de cooperativas de ahorro y crédito realizada por la Unión Cooperativa Nacional, Uconal, entidad de educación, asesoría y asistencia técnica que, en solo tres años, organiza en casi todos los municipios, parroquias, empresas económicas y en los barrios de la ciudades más importantes del país, cerca de 517 cooperativas. Todas ellas siguiendo el modelo de las credit unions norteamericanas y canadienses, cuya principal característica es el concepto aglutinante de"vínculo común", sea este de trabajo o residencia de la población asociada, que se da muchas veces en simultánea, además de otras acepciones en las cuales se pueda caracterizar dicho vínculo.

Del mismo modo, Uconal alienta con mayor vigor a las demás, cuando como referente impulsor propone a Coopdesarrollo e Indesco como agentes complementarios financieros y educativos.

En este periodo, la actividad de ahorro y crédito toma la delantera, no solo por el impulso de su ente integrador, sino por las circunstancias de consolidación con el que el sistema financiero mundial empieza a incidir en todas las interacciones y relaciones humanas y económicas.

\section{Tercer periodo (1965-1976): consolidación del cooperativismo}

Este periodo presenta algunas tendencias y características que destacan en el proceso evolutivo de las cooperativas del país. La primera de ellas es el debilitamiento de la cooperación de consumo que, después de un relativo auge en la década anterior, pierde su impulso y cede espacios ante la acción competitiva de los almacenes del Instituto de Mercadeo Agropecuario, Idema, y de las Cajas de Compensación Familiar que inician $y$, al decir de sus afiliados, "prestan sus servicios con eficiencia y buena organización". No obstante lo anterior, el Instituto Idema y la nueva política agropecuaria dan nuevos bríos a la forma cooperativa agropecuaria e impulsan aquella forma empresarial de cooperativa agroindustrial que da vida a aquellas de reforma agraria e impulsa políticas a través de Corveica.

La segunda característica refiere a que, según lo mencionan dirigentes de los organismos integradores mencionados antes, en textos institucionales, y según estudios apoyados por investigadores visitantes del Instituto de Estudios Cooperativo de Munster, Alemania, en 1975, como ente técnico colaborador de dos de los organismos integradores mencionados antes, la ma- yoría de cooperativas pertenecen a los empleados de grandes compañías, y se crearon como resultado de presiones de los sindicatos o por iniciativas de la misma empresa para prestar servicios a sus empleados. El modelo empresarial de consumo se menciona como errado, en tanto es montado como sección de este tipo de cooperativa que a su vez se propone multiactiva y de vínculo cerrado (al círculo laboral) y al mismo tiempo se ve impactado por fallas técnicas en el manejo y la orientación de las operaciones, lo que conduce, poco a poco, a las crisis financieras y operativas, y en consecuencia, a la decadencia de este tipo de cooperativa. Aquellas de consumo abiertas a públicos de residencia vecina, igualmente, salvo muy contadas excepciones, sucumben ante los embates del mercado expansivo.

La tercera característica es la iniciación de un tipo novedoso de cooperativa, producto del trabajo de un grupo de estudiantes de Indesco para optar al grado en Economía Social y Cooperativismo. Se trata de los colegios cooperativos que constituyen una nueva modalidad de empresa cooperativa. Estos colegios llegaron a solucionar un déficit educacional del país, especialmente en las zonas rurales y en los barrios marginados de las grandes ciudades, "Los primeros colegios se fundaron en 1965 y hoy (1975), el país cuenta con cerca de 200 cooperativas educacionales" (Benecke, Boettcher et al., 1992). Entre las tendencias nacientes, se observan propuestas de cooperativas de vivienda, en sus tres formas: para construcción comunitaria, para administración y para viviendas de propiedad cooperativa; tendencia que no presenta un desarrollo masivo, pero que muestra experiencias que incluso hoy siguen activas.

Es destacable en este periodo la conformación del Instituto de Financiamiento Cooperativo Financiacoop, figura financiera mixta que se propone como integrativa del sector cooperativo, pero a la vez con y por normatividad especial, reconocido como entidad de crédito, con aportes del Estado y bajo vigilancia de la entonces Superintendencia Bancaria. Este hecho coincide con la proliferación de obras, institucionales y de autores, o como la Liga de Cooperativas de Estados Unidos, en 1965, con su "Programa Interamericano de Desarrollo de Bancos para Cooperativas", que insisten en la necesidad de crear este tipo de entidades $y$ toda una estructura financiera propia a las cooperativas. Nótense las dos relaciones que se observan: de una parte, el avance de una concepción financista de la economía en general y, de otra, la relación por ausencia de dicha estructura. Cabe también señalar que este hito tiene incidencias sociales y económicas de auge y crisis que impactan el sector de cooperativas de ahorro y 
crédito en el periodo que sigue, especialmente en la década de 1980, con una gran oportunidad y apogeo frente a la crisis del sistema financiero tradicional, y en 1992 y siguientes, con crisis económica general de las economías, que arrastra con fuerza al sector, por supuesto, y en especial al de ahorro y crédito, no solo en Colombia.

\section{Cuarto periodo (1977-1990): crecimiento como sector y movimiento social}

Esta etapa es considerada de "tránsito de la simple noción de movimiento cooperativo hacia la configuración de un Sector Cooperativo de la economía" (Consejo Cooperativo Colombiano, 1975).

Tres hechos son hitos que caracterizan el periodo: el fortalecimiento y desarrollo de las cooperativas $\mathrm{y}$ de las organizaciones integrativas de grado superior; la creación de la Confederación Colombiana de Cooperativas, Confecoop, como organismo nacional de integración de todos los subsectores del movimiento cooperativo del país, y la expedición de la Ley 79 de 1988, como nuevo estatuto legal del sector cooperativo colombiano. No obstante todo ello, recibe la influencia de las tendencias dominantes: la preponderancia de lo financiero en el mundo, que se orienta a los mercados de capitales y secundarios con sus diversas innovaciones, y su equivalente en el sector, denominado para este periodo como sector social o economía social.

El número de cooperativas a diciembre de 1990 era de 3984; el de las pre-cooperativas, de 704; de los organismos de grado superior, de 115, para un total de 4803 entidades, que agrupan un total de 1534000 personas asociadas. El total de activos es de $\$ 515837$ millones de la época. Las principales instituciones auxiliares del cooperativismo en esa fecha eran la Universidad Cooperativa de Colombia, antiguo Indesco, y la Aseguradora Solidaria.

En el sector público, la vigilancia y el control, así como el fomento del cooperativismo, se ponen al cuidado del Departamento Administrativo Nacional de Cooperativas, Dancoop, creado mediante la Ley 24 de 1981, que sustituye a la Superintendencia Nacional de Cooperativas, erigida en 1933 mediante el Decreto 1339 de ese año, como una instancia con nivel homologado a instancia ministerial.

En 1981, los organismos cooperativos de grado superior y las instituciones auxiliares del cooperativismo del país, luego de un largo proceso, construyen la organización integrativa de tercer grado, que con el nombre de Confederación Colombiana de Cooperativas, Con- fecoop, es reconocida por el gobierno, mediante resolución número 2458 de 1981 . Como antecedentes de este delicado e importante proyecto, están la constitución del comité coordinador del cooperativismo colombiano en junio de 1977, la reunión en julio de 1978 del foro nacional cooperativo y la posterior reunión del Consejo Cooperativo Colombiano en el primer semestre de 1979.

Otro hecho significativo del periodo es la promulgación de la Ley 79 de 1988, que sustituye al Decreto Ley 1598 de 1963 como nuevo estatuto legal cooperativo que adecúa las disposiciones legales a los requerimientos de un movimiento en expansión y desarrollo acelerados. Es importante observar que, aunque esta nueva estructura gira alrededor de aquellas cooperativas que han logrado mejor desarrollo, esto es, las de ahorro y crédito - lo cual acentúa la asimetría con las demás formas cooperativas y de organizaciones sociales, populares-, estas últimas van posteriormente a verse identificadas con reclamar su identidad como de la economía solidaria.

De otra parte, pese a los logros legislativos, no se aporta la estructura necesaria para su autocontrol o la supervisión estatal adecuada, como lo veremos en el periodo siguiente, que inicia con los efectos de crecimiento de este, y sumen en la más profunda crisis al subsector de ahorro y crédito, convertido, en muchos casos, en financiero.

\section{Quinto periodo (1991-2010): crisis y economía solidaria o de la solidaridad}

En este periodo, se propone la economía solidaria, en general, y el cooperativismo, en particular. Del mismo modo, el periodo se caracteriza por dos situaciones aparentemente contrapuestas: una expansión notable y una crisis profunda en el subsector más dinámico, el de ahorro y crédito y financiero.

Uno de los hitos más importantes en el país de este periodo es el acto del 4 de julio de 1991, cuando la Asamblea Nacional Constituyente, convocada para introducir reformas fundamentales a la Carta política del país, promulga una nueva Constitución Política que deroga en todas sus partes la anterior. Esta nueva Carta, en su artículo 38, garantiza con gran amplitud el derecho de libre asociación para el desarrollo de las distintas actividades que las personas realizan en sociedad.

Varias disposiciones continuadas en los capítulos $2^{\circ}$ del Título II, artículos 58, 60 y 64, y el capítulo $1^{\circ}$ del título XII, artículo 333, hacen mención de la protección 
y promoción de las formas asociativas y solidarias de propiedad (art. 58); del deber del Estado de promover el acceso progresivo a la propiedad de la tierra de los trabajadores agrarios en forma individual o asociativa (art. 333). Cabe observar que "en la legislación previa a la nueva constitución no existía mayor precisión acerca de las expresiones formas asociativas y organizaciones solidarias" (Uribe, 1998, p. 181).

El reconocimiento constitucional de las actividades solidarias y cooperativas corresponde, sin duda alguna, al auge y desarrollo de las formas asociativas de ese carácter que en la década de 1990 presentan cifras importantes de cobertura y profundización en la economía del país y cuya cobertura social supera los $3 \mathrm{mi}-$ llones de personas.

A 1993 las entidades del sector solidario eran 8.872, de las cuales 5.630 eran cooperativas, 138 organismos de grado superior, 828 precooperativas, 1.868 fondos de empleados y 40 asociaciones mutualistas que prestan servicios a $2 ` 853.000$ asociados y a sus familias. A diciembre de ese mismo año las entidades de economía solidaria manejaban activos sociales por el orden de $\$ 2.061$ billones de pesos (Pineda, Castillo, Pardo y Palacios, 2006, p. 166).

La potencialidad del sector es atendida por los organismos de segundo grado del movimiento cooperativo mediante una serie de temas con prioridad, tales como: la planeación técnica y controlada del desarrollo; el fortalecimiento de los organismos de integración, tanto nacionales como regionales; la reestructuración y modernización de la entidad pública de inspección, control y vigilancia; la actualización legislativa cooperativa, especialmente para desarrollar las disposiciones de la nueva Constitución y estructurar un adecuado sistema de información del sector.

En 1999, según cifras del entonces Departamento Administrativo Nacional de Cooperativas, Dancoop, el sector solidario ofrecía las siguientes cifras estadísticas: entidades de ahorro y crédito, 4190; multiactivas, 1032; de transporte, 924; de trabajo asociado, 834; de servicios, 790; de comercialización, 759; de trabajo y servicios, 554; de productores, 431 ; de salud, 379; de educación, 328; de actividades agrícolas, 322; de vivienda, 265; de consumo, 260; de vigilancia, 67, y financieras, 63; para un total de 11198 organizaciones. En estas cifras se registran tanto las cooperativas como las precooperativas, los fondos de empleados, las asociaciones mutualistas, los organismos de grado superior y las instituciones auxiliares del sector.
Aparecen autores latinoamericanos e hispanoamericanos tales como Boaventura de Sousa Santos, que proponen una acción política como necesaria al reconocimiento de esa economía solidaria o de la solidaridad, desde las mismas organizaciones del tercer sector, solidarias y populares. Nótese que esta propuesta no ha podido ser acompañada de cifras y datos que se puedan validar, en tanto no se cuenta con una sola instancia, o una forma o caracterización unificadas, pues por el contrario existen múltiples formas, acepciones, actores y funciones, tanto formales y legalizados como informales y desconocidos para la estructura normativa y de control, pero que se pretenden incluidos en esta propuesta.

De otra parte, si bien la legitimidad social de la organización cooperativa viene dada por la conjugación del cumplimiento de sus tres funciones principales: la productiva, la económica y la de desarrollo social, las incidentes influencias de unas y otras tendencias hacen que en Colombia las cooperativas de ahorro y crédito, en un número significativo, se hayan dado a la tarea de múltiples transformaciones, primero en cooperativas multiactivas, pero a su vez, con desmutualización de sus operaciones luego de un fraccionamiento por escisión de sus secciones y operaciones, para acabar en una nueva figura, la de cooperativas financieras. Los hallazgos indican que difícilmente se logra encontrar que una cooperativa haya nacido directamente como multiactiva o financiera. No quiere decir esto que todas las cooperativas sufran el mismo proceso; por el contrario, la investigación pudo establecer con precisión qué cooperativas que nacieron de ahorro y crédito, al conservar su fundamentación, hoy se mantienen como tales, manteniendo su legitimidad social y de organización económica cooperativa, y son eficaces en su objeto económico y social.

\section{Tipología de las cooperativas en Colombia}

Cada tipo de cooperativa tiene su especificidad, su historia, sus éxitos y sus desafíos. El propósito en la investigación, entonces, se orienta a comprender la dinámica cooperativa; por ello, el estudio de caso permite analizar las particularidades, desde los procesos de cada tipo de cooperativa, el desarrollo, el beneficio e impacto social tanto entre y para sus asociados, como en su medio de acción e influencia.

Siendo las más representativas por su alcance, en cuanto a número y cobertura social, además de su radio 
de acción y el papel que desempeñan en el panorama nacional en su incidencia social y económica, la primera comparación se enfoca en aquellos casos más relevantes de entre los tipificados; esto es: cooperativa de ahorro y crédito, cooperativa multiactiva y cooperativa financiera, como se muestra en la tabla 1.
Como se observa en la tabla 1 , es la ley y la estructura normativa la que, a partir del último periodo, reglamenta los servicios, desde una óptica generalizada de servicios financieros, que es aplicada indiscriminadamente para las cooperativas de ahorro y crédito y las multiactivas con sección de ahorro y crédito,

Tabla 1

Comparativo de las cooperativas que pueden ejercer actividad financiera

\begin{tabular}{|c|c|}
\hline Entidad & Características \\
\hline $\begin{array}{l}\text { Cooperativa de ahorro } \\
\text { y crédito }\end{array}$ & $\begin{array}{l}\text { - Actividad de ahorro y crédito, no financiera ni de intermediación, en forma exclusiva y solo con sus asociados. } \\
\text { - Vigilancia y control: Superintendencia de Economía Solidaria. } \\
\text { - Ley } 79 \text { de } 1988 \text { y art. } 41 \text { de la Ley } 454 \text { de } 1998 . \\
\text { - Decretos y resoluciones con regulación específica a sus opciones de operación autorizada. } \\
\text { - Brinda servicios exclusivamente a sus asociados. } \\
\text { - Decisiones tomadas mediante ejercicio democrático del asociado por medio de voto, en relación de un asociado, un } \\
\text { voto. } \\
\text { - Capital variable e ilimitado, que crece/decrece de acuerdo con el aporte del asociado o su retiro. } \\
\text { - Distribución de excedentes entre los asociados o por capitalización del mismo. } \\
\text { - Vinculación por libre adhesión. } \\
\text { - Retiro voluntario. }\end{array}$ \\
\hline $\begin{array}{l}\text { Cooperativa multiactiva } \\
\text { con sección de ahorro } \\
\text { y crédito }\end{array}$ & $\begin{array}{l}\text { - Presta diversos servicios, en forma exclusiva y solo a sus asociados. } \\
\text { - Vigilancia y control: Superintendencia de Economía Solidaria. } \\
\text { - Arts. } 63 \text { y } 64 \text { de la Ley } 79 \text { de } 1988 . \\
\text { - Arts. } 39 \text { y } 43 \text { de la Ley } 454 \text { de } 1998 \text {. Regula las condiciones de entorno que permiten autorizar la sección. } \\
\text { - Decretos y resoluciones con regulación específica a sus opciones de operación autorizada. } \\
\text { - Decisiones tomadas mediante ejercicio democrático del asociado por medio de voto, en relación de un asociado, un } \\
\text { voto. } \\
\text { - Capital variable e ilimitado, que crece/decrece de acuerdo con el aporte del asociado o su retiro. } \\
\text { - Distribución de excedentes entre los asociados o por capitalización del mismo. } \\
\text { - Vinculación por libre adhesión. } \\
\text { - Retiro voluntario. }\end{array}$ \\
\hline Cooperativa financiera & $\begin{array}{l}\text { - Presta servicios a asociados y a terceros; compite en igualdad de condiciones con el sistema financiero tradicional, } \\
\text { aunque tiene restricción de operaciones bancarias y aquellas autorizadas a los establecimientos de crédito, pues no } \\
\text { es considerada como tal por el Estado. } \\
\text { - Control y vigilancia: Superintendencia Bancaria, hoy Superintendencia Financiera y de Sociedades. } \\
\text { - Estatuto orgánico del sector financiero. } \\
\text { - Ley } 79 \text { de } 1988 \text { y art. } 40 \text { de la Ley } 454 \text { de } 1998 . \\
\text { - Decretos y resoluciones con regulación específica a sus opciones de operación autorizada. } \\
\text { - Brinda servicio a asociados y a terceros sin discriminación. } \\
\text { - Decisiones previstas legalmente para que sean tomadas mediante ejercicio democrático del asociado por medio de } \\
\text { voto, en relación de un asociado un voto. Por su tamaño y complejidad, esto no es la realidad práctica, pues se hace } \\
\text { necesario un proceso de designación de delegación piramidal, en la cual, igualmente, los terceros ya tienen catego- } \\
\text { rización para participar, tanto en las asambleas como en estamentos de decisión y control. } \\
\text { - El capital, aunque sigue siendo variable e ilimitado, crece/decrece de acuerdo con el aporte del asociado o su retiro; } \\
\text { por exigencias legales homologadas a los establecimientos de crédito, de circunstancias de riesgos operacionales } \\
\text { y de los altos niveles de competitividad en los cuales se ve envuelta la cooperativa, debe definir: capital mínimo irre- } \\
\text { ductible, niveles de solvencia y estructura de coberturas. } \\
\text { - Distribución de excedentes entre los asociados o por capitalización del mismo. } \\
\text { - Muestra una tendencia, casi obligada, a incrementar el denominado capital institucional, conformado con reservas } \\
\text { patrimoniales, que se crean e incrementan mediante capitalización de excedentes, cuya titularidad es indetermi- } \\
\text { nada y se convierte en un pool de recursos de manejo excepcional e irrepartible entre los asociados, incluso a la } \\
\text { liquidación del ente. } \\
\text { - Persiste la vinculación por libre adhesión, no obstante no haya opción de otorgar diferenciales, con argumentacio- } \\
\text { nes de normatividad aplicable a configurar prácticas contra la libre competencia. } \\
\text { - Retiro voluntario. }\end{array}$ \\
\hline
\end{tabular}

Nota. Elaboración propia 
desconociendo y anulando, inclusive, las teorías de no intermediación que maneja la concepción cooperativa.

$\mathrm{Al}$ respecto, desde la nueva normatividad, la de ahorro y crédito ya no es una actividad que pueda ser organizada desde la iniciativa de los asociados y como iniciativa privada autónoma; ahora es la ley la que dictamina cuándo las cooperativas multiactivas y las de ahorro y crédito podrán ejercer dicha actividad, enmarcada como "financiera"; solo será posible para los interesados, siempre y cuando sea autorizado por la Superintendencia de la Economía Solidaria, sEs. Podrá ejercerse dicha actividad financiera cuando la cooperativa, además del cumplimiento minucioso de su acreditación legal, se vincule al seguro que le brinda el Fondo de Garantías de Entidades Cooperativas, Fogacoop, figura homóloga al Fogafin, y cuente con una estructura tecnológica adecuada.

A continuación se presenta una breve descripción que identifica las características de cada uno de los tipos de cooperativas mencionados en la tabla 1.

\section{La cooperativa de ahorro y crédito}

Este tipo de cooperativa, históricamente se organiza como una de "aportes y crédito"; esto es, solamente hace uso de los aportes a capital para sus operaciones, cuya labor ha tenido en Colombia, Latinoamérica y los países del tercer mundo o emergentes una singular importancia. Aunque sean de carácter "cerrado" con y por su actividad no financiera, prestan una ayuda fundamental a los asociados. Estas cooperativas, al iniciar, de acuerdo con los desarrollos normativos de los años 1990 y siguientes, han sido objeto de fuerte normatividad, no están autorizadas a prestar servicios de ahorro, no pueden recibirlos ni de sus asociados ni de terceros y mucho menos adelantar actividad crediticia con terceros no asociados. Para avanzar a cooperativa de "ahorro y crédito", deben acreditar numerosos años de experiencia en manejo de aportes, como recursos en custodia, una operación exitosa de crédito con sus asociados y correcto manejo de los riesgos crediticios y de cartera.

Las cooperativas que tradicionalmente venían atendiendo la actividad de ahorro y crédito antes de 1998, y aquellas que sean reconocidas como especializadas de ahorro y crédito a partir de la Ley 454 de dicho año, se encuentran autorizadas para captar ahorros y adelantar actividad crediticia, pero exclusivamente con sus asociados. No podrán hacerlo con terceros. El gran desacierto de la ley es aquel de catalogar la actividad de este tipo de entidades cooperativas como "financiera", en tanto ello implica la connotación de intermediación, concepto que contradice la naturaleza del acto cooperativo que se adelanta entre un asociado y su cooperativa, y deriva en otros elementos normativos que anulan la diferenciación y riqueza de dicho concepto y acto cooperativos.

Si bien es cierto que, en la actualidad, el sistema financiero comercial brinda apoyo a los microempresarios, a los empleados y, en general, a toda aquella persona que con mínimos ingresos se vincula al sistema, también es cierto que esto no era así anteriormente. Para que una persona de estrato económico bajo o de salario mínimo fuera atendida por este sistema, tuvo que darse el periodo de crisis de la década de los ochenta, el que también permitió evidenciar las circunstancias de usura e ilegalidad de sistemas como el gota a gota, que dan origen a respuestas surgidas como propuestas de microcrédito, y otras intermediadas por figuras en auge como fundaciones y ONG, más conocidas como tercer sector, desde la concepción norteamericana.

El acercamiento a estructuras normativas de control financiero, con simultánea incursión de los actores del sistema financiero tradicional al ahorro y crédito popular, vía su incursión con programas de microcrédito, igualmente hacen que las cooperativas de ahorro y crédito incluyan en las solicitudes que deben diligenciar los asociados requisitos e información más rigurosos. Las diferencias operacionales se han acortado, haciendo más confiables a las cooperativas, desde la perspectiva de una estructura financiera basada en control de riesgos, y más populares a los establecimientos bancarios.

No ocurre así en lo social y conceptual de base para las cooperativas de ahorro y crédito. Es la cercanía a sus asociados lo que les permite conocimientos y confianzas que brindan opciones de facilidad en cuanto a garantías crediticias, cálculo de capacidad de endeudamiento, mejores determinantes de percepciones y costos. De otro lado, la esencia de no intermediación y la estructura de una concepción de oferta beneficio por sobre utilidades facilitan tasas de interés bajas, hacen innecesarias las cuotas de manejo en la utilización de los productos, entre otras; es decir, son una alternativa que ha permitido popularizar el manejo y movilidad de recursos, que repercuten en cercanía e inserción de grupos antes no visibles incluso al sector financiero.

Cooperativas de ahorro y crédito como: Cooptenjo (Cundinamarca), Beneficiar (Nacional con sede 
en Bogotá), Cofinal (Pasto), Comuldesa (Socorro, Santander), Coprofesionales (Bucaramanga) son entidades que, estudiadas en profundidad, evidencian buenas prácticas, indicadores de eficiencia y efectividad social, además de aquellos económicos o financieros, en los servicios que prestan, tales como créditos, diversas modalidades de cuentas de ahorros, coberturas sociales con seguros y otras formas solidarias, alta facilidad de acceso, con utilización oportuna, racional y disciplinada por parte de los asociados usuarios de los mismos.

Las cooperativas de ahorro y crédito en el último periodo han diversificado su portafolio de servicios, han contribuido nuevamente y de buena manera al crecimiento del sector, en especial aquellas entidades que, una vez superada la crisis financiera de 1998, se han dado a la tarea de innovar y dar inicio a la elaboración de mecanismos que permitan crear nuevos programas, incursionar en el tema de las remesas y otros cada vez más pertinentes a las necesidades del segmento social que atienden. Este tipo de cooperativas muestran buenas prácticas de gobernabilidad y son innovadoras en estructuras de participación que aseguran la participación democrática; no obstante, es cada vez más difícil su gestión efectiva, dadas las circunstancias de complejidad y crecimiento.

Nuevamente se pone de relieve la importancia de la calidad, oportunidad y adecuación de una Superintendencia de la Economía Solidaria que vigile sus actividades y servicios financieros, y que con ello represente y respalde la necesaria credibilidad ante todas aquellas personas que pertenecen y se acercan a estos actores del sector económico cooperativo.

\section{La cooperativa multiactiva}

Este tipo de cooperativa puede ser constituida por un número mínimo de 20 asociados fundadores, quienes con sus aportes, cualquiera sea su monto, proporcionan la estructura para producir o proveerse de bienes o servicios que contribuyan a satisfacer sus necesidades. Se atienden varias de ellas al mismo tiempo, que son organizadas para ser prestadas u ofrecidas por parte de diferentes departamentos o secciones: ahorro y crédito, vivienda, salud, recreación, etc., de la misma cooperativa.

El tipo estudiado da cuenta de aquella cooperativa que posee sección de ahorro y crédito, y centra sus observaciones en relación con su tipo y los procesos de cambio y transformación. Resulta interesante observar que esta figura en los procesos de evolución de las cooperativas de ahorro y crédito es bastante incidente, como ya se mencionó antes, y se constituye en el siguiente eslabón, como figura de transformación jurídica, previo a las conversiones de las cooperativas financieras. Lo anterior tiene implicaciones de nuevo rumbo conceptual y tendencia, como se hace manifiesto en los casos Coomeva y los efectos observados en Coomultrasan, tema que para los investigadores tiene referencia particular a dicho fenómeno.

\section{La cooperativa financiera}

La cooperativa financiera, catalogada así en la Ley 454 de 1998, presta servicios de ahorro y crédito, tanto a asociados como a terceros no asociados, todo ello de acuerdo con lo prescrito en el estatuto orgánico financiero (EOF) que rige al sistema financiero y de capitales, y con reglamentos específicos que se le requieran o son expedidos por la Superintendencia del ramo.

En cuanto al aporte de los asociados, es común encontrar que la cuantía del mismo es pactada como una suma obligatoria mensual, que generalmente es mínima; y a su vez, el ahorro o vinculación a un portafolio de servicios financieros constituye un factor determinante en la asignación de los cupos de crédito. A partir de ello, la operación se rige por las tendencias, normas y prácticas del sistema en general.

Las líneas de crédito son similares en la mayoría de las cooperativas. Se establecen con base en las necesidades de los asociados y se reglamentan por el Consejo de Administración. Surgen entonces diversas líneas y conformación de paquetes o portafolios. Las determinadas particularidades conducen a detallar en el respectivo reglamento lo relacionado con montos del crédito, periodicidad de desembolsos, calendario y cuantía de amortizaciones, refinanciaciones y garantías por exigir al asociado.

Los aspectos anteriores, descritos sucintamente, conducen a identificar como la diferencia fundamental si el beneficiario del crédito es un asociado a la cooperativa o es un tercero (particular no asociado), lo cual eventualmente permite la fijación de las características del paquete en cuanto a interés y tipos de garantías aceptables.

\section{Entre el ser y el deber ser: desviaciones}

Los hechos cumplidos hacen las tendencias, que son aprovechadas y manipuladas fácilmente por intereses particulares, en una sociedad que no tiene criterios 
ni ética colectiva, y que olvida tan rápido como le conviene.

No es que no se hayan dicho las cosas a tiempo. El doctor Mansilla (2002) lo advierte, y es aún más explícito el doctor Fisher (1998) cuando, invitado por Coopdesarrollo, entre las razones que expresa para dar respuesta a la pregunta ¿qué causa la crisis de las cooperativas financieras?, les dice a sus directivas, y así lo expresa en entrevista para la revista de la entidad:

Podemos estar de acuerdo que el gobierno no ha sido una gran ayuda para la prosperidad de las cooperativas de ahorro y crédito CAC [...] podemos afirmar con un buen grado de certeza que el factor determinante (si bien no el único) para distinguir a las CAC solventes de las insolventes es, si los administradores han abusado o no de los fondos confiados a ellos por los miembros [...] [y concluyentemente afirma] Si bien el largo brazo del regulador puede influir, la verdadera batalla se juega dentro de la institución [...] (las cursivas son añadidas).

Hace referencia en estas apreciaciones al buen gobierno cooperativo. La preocupación se centra en tratar de dar respuesta al principal interrogante planteado desde la investigación: ¿Cuál ha sido la incidencia de las diversas prácticas de ahorro y crédito en las cooperativas de Colombia en el desarrollo social y doctrinal del mismo sector?

En este sentido se puede señalar que, en la segunda mitad de la década de los años 1990, se evidencia una situación de crisis que exige una intensa, agresiva y rápida acción gubernamental, complementada con una reglamentación legal de la actividad financiera cooperativa, la cual se da a través de la Ley 454 de 1998. Se establecen normas sobre capital mínimo necesario para la constitución, capital mínimo e irreducible durante la existencia de la cooperativa, definición de actividades autorizadas, régimen de inversiones, normas sobre patrimonio básico y técnico, exigencia de fondo de liquidez, inscripción obligatoria en el Fondo de Garantías de Entidades Cooperativas, Fogacoop, niveles de supervisión y otras disposiciones que son de práctica común en el sistema financiero colombiano.

Esta situación puede describirse como una "muerte anunciada", parodiando el título de la novela del nobel de literatura, Gabriel García Márquez. Era de esperarse, cuando se transita hacia lo financiero sin una adecuada estructura de aseguramiento y control, como bien lo sugerían los autores y organismos internacionales, desde el periodo de expansión en los años sesenta del siglo pasado.
La situación de crisis desde1998 y hasta 2008 produce efectos negativos importantes e incide gravemente con cuantiosas pérdidas económicas en algunas cooperativas, con perjuicio para innumerables asociados y algunos ahorradores, pérdida de confianza y credibilidad en el sector cooperativo, situación de quiebra y desaparición forzada de los bancos cooperativos existentes - que termina siendo aprovechada por el sector de capitales, en la venta de un banco cuyo origen es de cooperativas (Megabanco) a uno de los bancos comerciales (Banco de Bogotá)-, la dispersión de recursos hacia otras instituciones del sector lucrativo, más otra serie de efectos negativos que marcan al sector y se derivan de la aludida situación.

La investigación permite visualizar cómo la evolución, el desarrollo y las crisis por las que ha atravesado el sector cooperativo en cada etapa han aportado valiosas experiencias y enseñanzas que bien vale la pena analizar, repensar y proyectar, para así poder nutrir los nuevos procesos cooperativos que hoy se dan cuando se dice: "La propuesta cooperativa en alza" (CastilloSandoval, 2014), y se muestran cifras bastante interesantes del sector, frente a aquellas de las 1001 empresas referenciadas en la revista.

Las prácticas observadas a finales de la década de los años 1990 evidencian francos desvíos a la esencia de las cooperativas, las cuales, en lugar de potenciar su papel en cuanto al desarrollo social, pierden todos sus esfuerzos históricos, no solamente en los aspectos económicos o financieros.

La mayor pérdida, con incidencia lamentable, ha sido la pérdida del capital social y de la riqueza social acumulada, incalculable y difícil de reconstruir para el país.

El traslado de expectativas de obtención desmedida de ganancia, concepto propio de una óptica de capitales e inversiones, da al traste con su doctrina. Este mal se extiende como pólvora encendida, y afecta o favorece la entrada de otras tesis y propuestas muy liberales unas y otras muy insistentes a favor de un asociacionismo muy inclinado a fines de acción política, y propuestas en aras de políticas públicas teóricamente socializantes. $\mathrm{Al}$ respecto se observa como tendencia con varios ejemplos en nuestro continente.

La primera conclusión del estudio apunta a que uno de los aspectos que más ha influido para y después de la crisis que golpeó a este tipo de empresas fue la pérdida de sus valores, ya que sus actividades fueron cambiando y, aparejado con esto, desviando el propósito con el cual se habían creado, como cooperativas. 
Estos valores y referentes en las cooperativas financieras se fueron perdiendo de manera evidente y acelerada con el paso del tiempo, producto del afán de buscar el lucro. Al perderse estos valores, las cooperativas olvidan que sus utilidades son propiedad colectiva y su fin es promover la unión voluntaria de personas, las cuales tienen intereses y necesidades comunes y en las que deben primar valores principales como la solidaridad y la ayuda mutua, sin jerarquías.

Otro de los principios que se desvío por parte de las cooperativas fue el de distribución de excedentes en proporción a las operaciones. El sistema cooperativo financiero no aplica la teoría de retorno en proporción a las operaciones como está contemplado en su modelo e incluido en el texto de la Ley cooperativa 79 de 1988 en su artículo 4: "reintegrar a sus asociados parte de los mismos en proporción al uso de los servicios".

Si se hubiese mantenido su práctica correcta, el debilitamiento económico de las cooperativas no habría sido tan acentuado y, por el contrario, las habría puesto en posición fortalecida, en la medida que sus asociados, adicional a apreciar la justeza en la retribución a su vínculo, hubieran destinado estos recursos a engrosar los aportes sociales, tal como lo explica el principio en mención. Por el contrario, la evidencia es que muchas cooperativas decidieron acreditar a los socios los excedentes en proporcionalidad distinta a la base de las actividades o servicios tomados en su cooperativa, e incluso, en algunos casos fueron distribuidos a terceros no asociados, como práctica soportada en una titularidad ficticia y mercantil de vinculación como usuario.

Este error garrafal de aplicación por interpretación quiebra el eje del modelo cooperativo, convierte una práctica en tendencia que transforma la teoría y es universalmente aplicada. Así, hoy vemos cómo muchas cooperativas distribuyen los excedentes en proporción a los aportes de capital social que acredita cada asociado.

De esta forma se puede argumentar que, desde el punto de vista de su causa y origen, el retorno cooperativo no puede asimilarse al dividendo. El primero se concibe en función de la actividad económica realizada por el socio con la sociedad cooperativa, y el otro, por la participación de un socio inversionista en el capital social de una empresa, que por esa misma razón es de capitales.

Por confusiones en estos dos aspectos se empieza a aceptar que los retornos cooperativos sean igualmente confundidos con los dividendos en términos legales $\mathrm{y}$ fiscales. Los retornos cooperativos no son rendimientos del capital.
El desvío en la práctica de la democracia participativa por una representativa, al igual que la desigualdad promovida por la insistencia en derechos individuales e individualistas por sobre los colectivos y de bien común, entre otros, se suman a otras causas que evidencian la desviación en cuanto a los principios y valores de las cooperativas que aumentaron la crisis.

Lo más grave observado desde las evidencias, en todo este entramado complejo de falencias y malas prácticas, es que se abre paso desde aquella época, a una insistencia por la primacía de intereses individuales sobre los colectivos. Lo anterior representa el mayor desvío entre el ser y el deber ser para estas empresas, básico alejamiento y pérdida de observación de los principios y valores cooperativos como referentes, hecho que es agravado por un crecimiento sin adecuada planeación, fallas protuberantes en el control ejercido por los entes internos, externos y reguladores, además de ausencia de apoyo oportuno y eficaz del Estado al sector.

\section{Conclusiones}

En este panorama es importante resaltar que se tienen hallazgos importantes de autorreflexión y juicio que se llevan a cabo en las mismas cooperativas, sobre las causas de la crisis, los efectos, la incidencia de decisiones estratégicas que tomó la cooperativa para enfrentar la crisis, así como sobre quién o quiénes ayudaron a resolverla.

La pérdida de identidad, inoportuno e ineficaz autocontrol público, por querer asemejarse demasiado, "terminan por olvidar que la gran ventaja reside precisamente en el hecho de ser diferente; dicho de otro modo, las cooperativas corren el riesgo de ver que la victoria se les va de las manos por haber pretendido combatir el enemigo en su propio terreno con sus propias armas" (ACI, 1980, p. 184).

Las cooperativas son empresas no capitalistas, sin ánimo de lucro, y que, para el caso del subsector estudiado, se diferencian de un banco privado por su forma de propiedad, de gestión y de reparto de sus beneficios y resultados, que no son utilidades.

$\mathrm{El}$ argumento que se plantea como relevante es la desconfianza en el sistema cooperativo financiero, y el desconocimiento de las bondades que, aun con las innovaciones incluidas, sigue teniendo el modelo. Adicionalmente, las fallas protuberantes que continúan, como son la falta de políticas oficiales eficaces y pertinentes al sistema, concentración de poder, inexistencia 
de una cultura de autocontrol y ausencia de organismos oficiales de control.

Se observa que las cooperativas de ahorro y crédito procuran en su gestión sostener una práctica de redistribución de la riqueza. Esto no es tan evidente en las multiactivas con sección de ahorro y crédito, ni en las financieras.

En las financieras estudiadas, en tanto sus preocupaciones ya no son orientadas prioritariamente por satisfacer necesidades identificadas, pues están concentradas en mantener las tasas de crecimiento de vinculados o por su participación en los mercados donde han incursionado, se reitera la preocupación por lo que significa la nueva situación de Coomeva al convertirse en banco y las tendencias observadas en las cooperativas que siguen esta tendencia.

La incidencia de las cooperativas de ahorro y crédito estudiadas y su contraste con el perfil de cada tipo muestran evidencias ciertas de mayor impacto en el mejoramiento del nivel de vida de sus asociados; numerosos testimonios se logran espontáneamente. Se observa que el involucramiento de este tipo de cooperativas en poblaciones, barrios o grupos es significativo, son muy apreciadas, y algunas de ellas se constituyen en eje de la vida comunitaria de la localidad.

La cooperativa multiactiva con sección de ahorro y crédito, al igual que las nuevas formas de cooperativa financiera presentes, si bien son apreciadas por las comunidades, se observa que lo son en igualdad frente a las demás instituciones financieras, tomadas como un medio más u opción de financiamiento, pero no de involucramiento o fuente de mejores opciones y participación en riqueza social.

Definitivamente se hace evidente que las cooperativas financieras no son percibidas como diferenciadas de los demás actores del sector financiero tradicional, percepción que se acentúa por su acelerado crecimiento en número de usuarios y muchas veces alta rotación para sustitución de clientes, resultado de peregrinas estrategias de mercadeo.

La comparación entre los modelos nacionales influyentes y las prácticas de ahorro y crédito de las organizaciones cooperativas colombianas permite identificar semejanzas y diferencias con incidencias fuertes en lo doctrinal, social, organizacional, empresarial, y prácticas de impacto en sí mismas y en el entorno.

Las prácticas cooperativas en la modalidad de ahorro y crédito - multiactiva y financiera- han tenido en Colombia la influencia de sistemas o movimientos de gran importancia en el ámbito mundial, representados en particular por organismos internacionales de su misma naturaleza, como la Secretaría de Educación, de su cúpula organizativa mundial (World Council of Credit Unions, woccu), cuya gestión se centra en hacer transferencias tecnológicas y de programas tales como microfinanzas, servicios Sumared, Sugiro y otros. Igualmente lo hacen con vigor entidades ONG internacionales, con presencia especial de la Iglesia católica, que con su doctrina social inciden con fuerza en la práctica y usos de lo social. También lo hacen los modelos financieros de Basilea, los cuales aunque modelos no cooperativos, igualmente hacen presencia, modelan y hacen girar los centros de atención de estas entidades.

Los factores críticos observados y que han tenido efectos devastadores unos, positivos otros, llevan al reconocimiento de la identidad de las cooperativas y a la conciencia de su propia naturaleza. Así, toda cooperativa que tiene claros sus derroteros, ha desarrollado estrategias propias y acordes con el contexto de las comunidades donde se hacen presentes, y se posiciona como un magnífico agente económico y social.

Permanece la inquietud sobre las transformaciones que sufre su axiología y prácticas, ante lo cual surge la pregunta: ¿estamos abocados a una nueva crisis o asistimos a una continuación de la misma en este tipo de organizaciones?

Las cooperativas de ahorro y crédito, las multiactivas e incluso las financieras siguen su proceso, muchas de ellas desarrollando buenas prácticas con gran aporte, al punto de potencializar su dimensión social y consolidación de organización con respecto al mejoramiento de la comunidad local y nacional.

El estudio pudo corroborar que las diversas prácticas de ahorro y crédito de la organización cooperativa cuentan con un fundamento doctrinal, teórico, metodológico y una política de acción que, aplicados unificadamente, permiten su proyección con incidencia más eficaz en cuanto al desarrollo social y económico de las personas y de las comunidades. Al cumplir su papel de manera correcta, se convierten en eficaces agentes promotores de cambio social. Las otras formas financieras cooperativas también lo hacen, en menor proporción, y su incidencia es fundamentalmente de cobertura e inclusión por tamaño, aunque al hacerlo de manera no diferenciada frente a los otros actores del mercado no se justifican ni en su naturaleza ni en las condiciones de beneficios fiscales, y a la vez de bloqueo y barreras de mercado que enfrentan. 


\section{Referencias}

Alianza Coopertaiva Internacional, ACI. (1980). Las cooperativas en el año 2000 (Parte v). En Acta Congreso Mundial ACI., Moscú.

Benecke, D. W., Boettcher, E. et al. (1992). Cooperativismo, instrumento de desarrollo en un orden libre. Bogotá: Ascoop.

Castillo-Sandoval, D. (2014). Cooperativas: un impulso económico y social al país. Portafolio, 12, 32-33.

Congreso de la República de Colombia. (1932). Ley 31 de 1932. Bogotá: Congreso de la República.

Congreso de la República de Colombia. (1968). Decreto 2059. Por el cual se reglamenta el Decreto 1598 de 1963 que actualiza la legislación cooperativa. Bogotá: Congreso de la República.

Congreso de la República de Colombia. (1981). Ley 24 de 1981. Por la cual se Transforma la Superintendencia Nacional de Cooperativas en Departamento Administrativo Nacional de Cooperativas, se fijan sus objetivos, estructura y funciones, se provee a su dotación presupuestal $y$ se dictan otras disposiciones. Bogotá: Congreso de la República.

Congreso de la República de Colombia. (1988). Ley 79 de 1988. Marco conceptual que regula el acto cooperativo y al sector cooperativo. Bogotá: Congreso de la República.

Congreso de la República de Colombia. (1998). Ley 454 de 1998. Por la cual se determina el marco conceptual que regula la economía solidaria. Bogotá: Congreso de la República.

Consejo Cooperativo Colombiano. (1975). Configuración del sector cooperativo. Bogotá: Sesión No. 03.

De Sousa Santos, B. (2006). Reinventar la democracia: reinventar el Estado. Buenos Aires: Consejo Latinoamericano de Ciencias Sociales, Clacso. Disponible en http:// bibliotecavirtual.clacso.org.ar/se/20100613090848/reinventar.pdf
Fabra, A. (1944). Las modernas corrientes económicas y las enseñanzas de Santo Tomás de Aquino. (Manuscrito). Medellín.

Fabra, A. (1945). La cooperación: su porvenir está en las Américas (3a ed.). Medellín: Ediciones Universidad de Antioquia, Instituto de Estudios Cooperativos del Cauca.

Fisher, K. (1998). ¿Qué causa la crisis de las cooperativas financieras? Revista Coopdesarrollo, 1(84), 15.

Fouquet, G. (1944). El sector cooperativo. Buenos Aires: Intercoop.

Mansilla, M. A. (2002). Por una empresa de democracia económica, Corfincora 40 años. Bogotá: Graficoop.

Pardo, L. P., Serrano, R. y Jaramillo, G. (2006). Estado del arte del sector solidario en Colombia. Bogotá: Editorial Universidad Cooperativa de Colombia.

Pineda, C. J., Castillo, M. E., Pardo, E. y Palacios, N. (2006). Cooperativismo mundial (3a ed.). Bogotá: Consultamerica, Grupo Asesor.

Presidente de la República de Colombia. (1993). Decreto 663 de 1993. Por medio del cual se actualiza el Estatuto Orgánico del Sistema Financiero y se modifica su titulación y numeración. Disponible en: http://www.supersociedades.gov.co/Web/Decreto/Decreto_663_1993.htm

Uribe, C. (1998). Crisis ideológica del cooperativismo a la luz del pensamiento de Alexander Fraser Laidlaw. Bogotá: Ediciones Guadalupe, Fondo Nacional Universitario.

Uribe, C. (2004). Crisis ideológica del cooperativismo (4a ed.). Bogotá: Ediciones Guadalupe, Fondo Nacional Universitario. 